\title{
Ferrous Fibre Network Materials for Jet Noise Reduction in Aeroengines Part l: Acoustic Effects**
}

\author{
By I. O. Golosnoy, J. C. Tan and T. W. Clyne*
}

Noise emitted by gas turbine aeroengines is of major concern. For turbofan engines, it comes from two main sources the rotational motion of the system (fan, compressor and turbine) and gas mixing phenomena associated with the jet emerging from the rear of the engine ("jet noise"). Most rotation-generated noise occurs at well-defined frequencies (dependent on engine speed), whereas jet noise tends to be more broadband. Fan/compressor/turbine noise normally dominates during landing and is of comparable amplitude to jet noise during cruising. Fan noise can be reduced by using acoustic liners and by redesigning the inlet lip to make the inner wall of the nacelle sound-absorbent, and by reshaping the fan blades - for example so that they tend to dissipate local shockwaves.

Jet noise (including any contributions from mixing of core/combustion and by-pass streams) is mainly associated with turbulent flow in the exhaust region. It is the dominant acoustic source during take-off, and is hence of prime concern. Unfortunately, jet noise is hard to control, since any

[*] Dr. I. O. Golosnoy, Dr. J. C. Tan, Prof. T. W. Clyne

Department of Materials Science $\mathcal{E}$ Metallurgy

Cambridge University

Pembroke Street, Cambridge CB2 3QZ, UK

E-mail: twc10@cam.ac.uk

[**] Funding for this work has been provided by EPSRC, through a Platform Grant, and by DTI, via a Technology Programme project involving Avcen Ltd and Fibretech Ltd. The concept of using highly porous metallic modules for these purposes arose from original discussions with the chief executive of Avcen, Mr. Mike Dacre. The authors are particularly grateful to Lee Marston, of Fibretech, who supplied the acoustic modules and has been responsible for several technological developments involved in their production, and to Kevin Roberts, of the Materials Science Department in Cambridge, for extensive technical assistance. In addition, there have been a number of productive scientific and technical discussions with Dr. Panos Laskaridis, of Avcen, and Dr. Iain Dupere, of the School of Mechanical, Aerospace and Civil Engineering in Manchester University. There has also been valuable input from several members of the committee overseeing the DTI project, notably Prof. Jeff Jupp and Dr. Mike Winstone (DSTL). measures must exert their effect before the exhaust leaves the engine. In fact, Lighthill's eighth power law (linking noise intensity to gas velocity), and its consequence of high-bypass ratio (low gas velocity) engines tending to allow lower noise levels for a given thrust, remains a pre-eminent design guideline. Other design changes aimed at reducing jet noise have had limited success. Recent developments include nozzle designs incorporating chevrons ${ }^{[1,2]}$ to control mixing of core and by-pass streams and exhaust designs promoting mixing of core, by-pass and ambient airflows, both of which are reported to give up to $\sim 3 \mathrm{~dB}$ noise reduction. Broadband noise reduction can also be achieved using active absorption systems, ${ }^{[3,4]}$ but these rely on rapid and complex feedback control. In general, they are considered unlikely to be effective on most aircraft, at least in the near future.

Increased exhaust containment length, with a module made of a suitable acoustic attenuation material in the enclosed region, has good potential for reduction of jet noise. Open cell porous materials are promising candidates. Acoustic absorption within them ${ }^{[5-7]}$ results mainly from drag on acoustic waves as they propagate through narrow, tortuous channels. The frequency characteristics of such absorption should be taken into account, and related to the frequency sensitivity of the human ear. The well known Fletcher-Munson curves $^{[8]}$ indicate maximum sensitivity at around 1-6 kHz. Frequencies below a few hundred $\mathrm{Hz}$ and above $\sim 10 \mathrm{kHz}$ are unlikely to be problematic. There have been relatively few studies on the effect of the architecture of porous materials on the frequency dependence of their sound absorption characteristics. Xie et al. ${ }^{[7]} \mathrm{did}$, however, report that, in their work on directionally-solidified porous copper with porosity in the approximate range of $40-60 \%$, sound absorption increased with increasing frequency, from a low level below $\sim 1 \mathrm{kHz}$ to a broad peak somewhere between 2 and $5 \mathrm{kHz}$. They also established that sound absorption was more effective with higher porosity levels and finer pore diameters (although they only covered the range of 660 to $460 \mu \mathrm{m})$.

It has also been reported that sound absorption at the lower end of the frequency range of interest $(\sim 1-3 \mathrm{kHz})$ can be improved by using 'double-porosity ${ }^{\prime[9,10]}$ multilayered ${ }^{[11-13]}$ or stratified $^{[14,15]}$ porous structures. To date, however, very few studies have been carried out on the acoustic properties of porous materials at high temperatures ${ }^{[16]}$ and/or in a rapid gas flow environment, such as that in the exhaust of a gas turbine aeroengine. 
The thermal environment in jet engine exhausts (peak gas temperatures of $\sim 700-800^{\circ} \mathrm{C}$ ) rules out all polymeric and macromolecular materials, but various metals and ceramics are stable at these temperatures. However, the thermo-mechanical stability requirements generated by exposure to thermal shock, thermal cycling, mechanical vibration and high velocity (up to $\sim 300 \mathrm{~ms}^{-1}$ ) gas impact are quite demanding. Metals are much more likely to be able to meet these requirements than ceramics. Moreover, while many types of highly porous metal exhibit relatively poor toughness (under tensile loading) and mechanical durability, ${ }^{[17-20]}$ metallic fibre network materials can be relatively strong and tough, particularly if the fibre-fibre joints are strong. ${ }^{[1]}$ Of course, a low overall density is highly desirable, to minimise the mass of the module.

The present study is thus focussed on highly porous metallic materials made by bonding ferrous fibres into an open network. These materials offer a lot of scope for tailoring of network architecture, ie void content, void connectivity and scale (and hence properties such as gas permeability and thermal conductivity), and also the incorporation of anisotropy and heterogeneity (such as gradients of void content). The technique of computed X-ray tomography has proved to be a powerful tool ${ }^{[22]}$ in characterising the local fibre network architecture and this is facilitating the design and processing of tailored structures. The present work is mainly concerned with the acoustic attenuation performance of fibre network modules with specified shape and internal architecture. An important aim has been to separate any effect of introducing such a module on the gas flow patterns and velocities (and hence on the creation of jet noise) from genuine absorption of sound within the module. It might be envisaged that modules could be designed (for particular engines) giving noise reduction via both mechanisms, but of course account must be taken of any effect that gas flow modification might have on engine performance (thrust, fuel consumption and general stability).

\section{Experimental Procedures}

\section{Fibre Network Material Production}

The study reported here has been carried out using 304 stainless steel fibres, manufactured (by Fibretech Ltd) using a melt extraction procedure. This grade of stainless steel is known to have good high temperature corrosion resistance and to exhibit a good combination of mechanical properties and suitability for various types of processing - see Part II of this pair of papers. These fibres have an approximately crescent-shaped section, with an average diameter of about 50-100 $\mu \mathrm{m}$, although there are significant variations from fibre to fibre and along the length of individual fibres. Both short ( $5 \mathrm{~mm})$ and continuous fibres have been used. Based on experience in the production of sandwich panels with sintered fibre cores, ${ }^{[21-24]}$ the network materials were produced by sintering in vacuum, typically for about 1-2 hrs at $1200{ }^{\circ} \mathrm{C}$. Figure 1 (a) shows a micrograph of a typical material.

The materials used in the present work, and information about their dimensions and internal structure, are listed in Table 1. The modules are all cylindrical in shape. In some cases, there was a radial increase in relative density. The objective in producing such specimens was to explore the possibility of sound absorption being enhanced by a low density where sound waves enter the material (to reduce reflection), but a higher density in the interior (giving increased specific surface area and hence greater sound attenuation). Graded density modules were produced by separately sintering thin sheets, using different consolidation pressures, and then bonding them together. Information about the nozzle-module gap, tubular enclosure, thrust measurement and fuel supply voltage (see Tab. 1) are given below.

\section{Material Characterisation}

Fibre network materials may be regarded as lying somewhere between a conventional material and a structure. Comprehensive characterisation is thus required if such material is to be optimised for particular applications. This relates
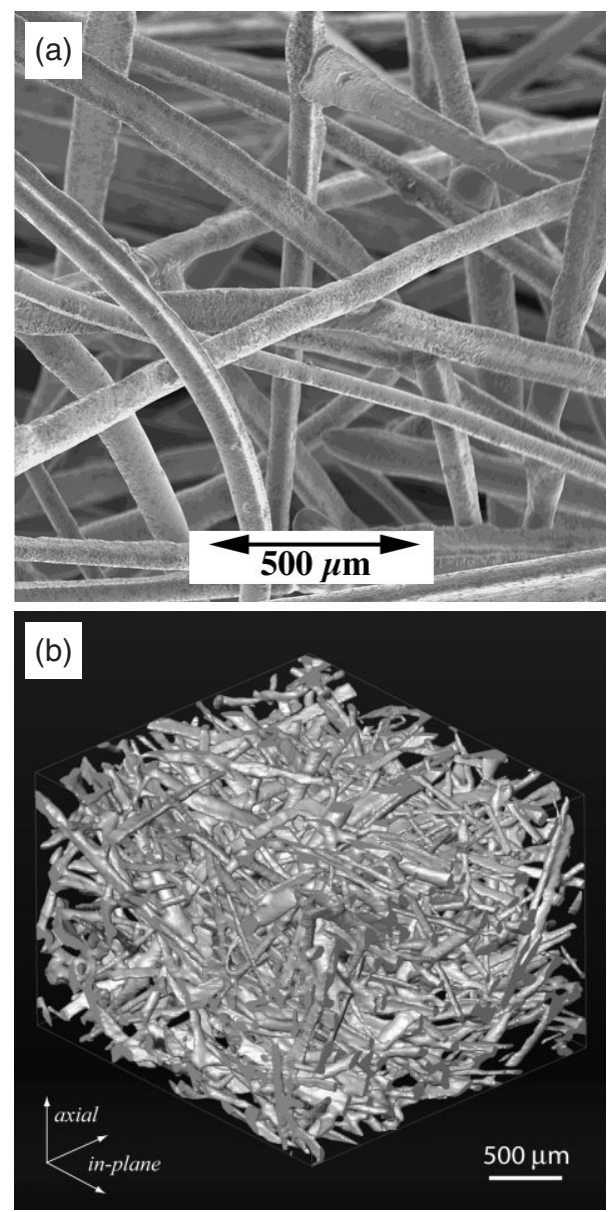

Fig. 1. a). SEM micrograph and .b) tomographic visualisation of a typical fibre network material. 
Table 1. Module/set-up characteristics, and measured engine thrust and fuel consumption rate, for each run.

\begin{tabular}{|c|c|c|c|c|c|c|c|c|c|}
\hline \multirow{2}{*}{$\begin{array}{l}\text { Run } \\
\text { Code }\end{array}$} & \multicolumn{3}{|c|}{ Module Dimensions (mm) } & \multicolumn{2}{|c|}{ Relative Density (\%) } & \multirow[t]{2}{*}{ Gap? } & \multirow[t]{2}{*}{ Tube? } & \multirow[t]{2}{*}{ Thrust (N) } & \multirow{2}{*}{$\begin{array}{c}\text { Fuel Signal } \\
\text { (V) }\end{array}$} \\
\hline & Bore & Wall thickness & Length & Average & Range & & & & \\
\hline 1 & & No module & & & & Yes & No & 164 & 4.88 \\
\hline 2 & 60 & 1.5 & 94 & 100 & - & No & No & 131 & 4.51 \\
\hline 3 & 60 & 1.5 & 188 & 100 & - & No & No & 132 & 4.54 \\
\hline 4 & & No module & & & & Yes & No & 92 & 2.96 \\
\hline 5 & & No module & & & & Yes & No & 112 & 3.41 \\
\hline 6 & & No module & & & & No & Yes & 85 & 3.28 \\
\hline 7 & 58 & 20 & 188 & 13.5 & $5-20$ & No & No & 93 & 3.24 \\
\hline 8 & 58 & 20 & 188 & 13.5 & $5-20$ & Yes & No & 93 & 3.28 \\
\hline 9 & 58 & 10 & 188 & 12.5 & - & No & No & 90 & 3.52 \\
\hline 10 & 58 & 10 & 188 & 13 & 5-20 & No & No & 90 & 3.33 \\
\hline 11 & 58 & 20 & 188 & 13.5 & 5-20 & No & No & 89 & 3.33 \\
\hline 12 & 58 & 20 & 47 & 13.5 & 5-20 & No & No & 111 & 3.62 \\
\hline 13 & 58 & 20 & 94 & 13.5 & 5-20 & No & No & 111 & 3.69 \\
\hline 14 & 58 & 20 & 235 & 13.5 & 5-20 & No & No & 111 & 3.98 \\
\hline 15 & 250 & 7 & 260 & 17.5 & - & No & Yes & 84 & 3.43 \\
\hline
\end{tabular}

partly to fibre (and joint) microstructure, which will affect properties such as yield strength and resistance to creep and fatigue. However, the features of prime interest in the present paper (concerning acoustic properties and gas permeation characteristics) are expected to be largely independent of metal microstructure, but sensitive to network architecture. The technique of computed X-ray microtomography, which allows the surface topography to be captured, has thus been used. A visualisation of a typical fibre network material is shown in Figure 1(b). Recently-developed skeletonisation algorithms $^{[22]}$ allow such topographic data to be converted to architectural characteristics, such as distributions of fibre segment length (aspect ratio) and fibre orientation. The average density (void content) can also be obtained. The volume over which such analyses are carried out is typically of the order of a $10-20 \mathrm{~mm}^{3}$. Since typical wall thicknesses of materials studied here are $\sim 10-20 \mathrm{~mm}$, it's also possible to characterise structural gradients using microtomography.

\section{Engine Specifications, Acoustic Measurements and Engine Performance Data}

The engine employed in this work was a Pegasus HP E-Start, supplied by AMT Netherlands. It is a turbojet engine, with no by-pass air flow. The main technical specifications are shown in Table 2. Most of the experimental data presented in this paper refer to runs carried out with throttle settings of around $70-80 \%$ of the maximum, and corresponding engine speeds of about $90-100 \mathrm{krpm}$. The fuel consumption
Table 2. Technical data for AMT Pegasus HP E-Start turbojet engine.

$\begin{array}{cc}\text { Diameter } & 120 \mathrm{~mm} \\ \text { Length } & 342 \mathrm{~mm} \\ \text { Weight } & 2.255 \mathrm{~kg} \\ \text { Maximum Thrust } & \sim 160 \mathrm{~N} \\ \text { Maximum Engine Speed } & \sim 120,000 \mathrm{rpm} \\ \text { Pressure Ratio at Max. Speed } & 3.2: 1 \\ \text { Air Flow Rate at Max. Speed } & 0.375 \mathrm{~kg} \mathrm{~s}^{-1} \\ \text { Fuel Type } & \mathrm{kerosene}^{-1} \\ \text { Max. Fuel Consumption Rate } & 7.5 \mathrm{~g} \mathrm{~s}^{-1}\end{array}$

rate is proportional to the signal voltage sent to the fuel pump (see Tab. 1), with $1 \mathrm{~V}$ corresponding to $1.55 \mathrm{gs}^{-1}$ of kerosene consumption.

The complete experimental set-up is illustrated in Figure 2. The engine was located in the centre of an enclosed square courtyard, about $10 \mathrm{~m}$ in side length, with walls about $5 \mathrm{~m}$ in height. A Samson C01 condenser microphone was used, with a sensitivity of $-33 \mathrm{~dB} \mathrm{~Pa}^{-1}$ and a maximum Sound Pressure Level (SPL) of $136 \mathrm{~dB}$. Data acquisition was carried out using Audacity ver. 1.2 software, with $88.2 \mathrm{kHz}$ sampling rate and 16 bit precision (covering a $96 \mathrm{dBFS}$ range). Microphone and circuit gains were set to $-20 \mathrm{~dB}$, so that a recorded value of $0 \mathrm{dBFS}$ ( $\mathrm{dB}$ Full Scale) corresponds to approximately 

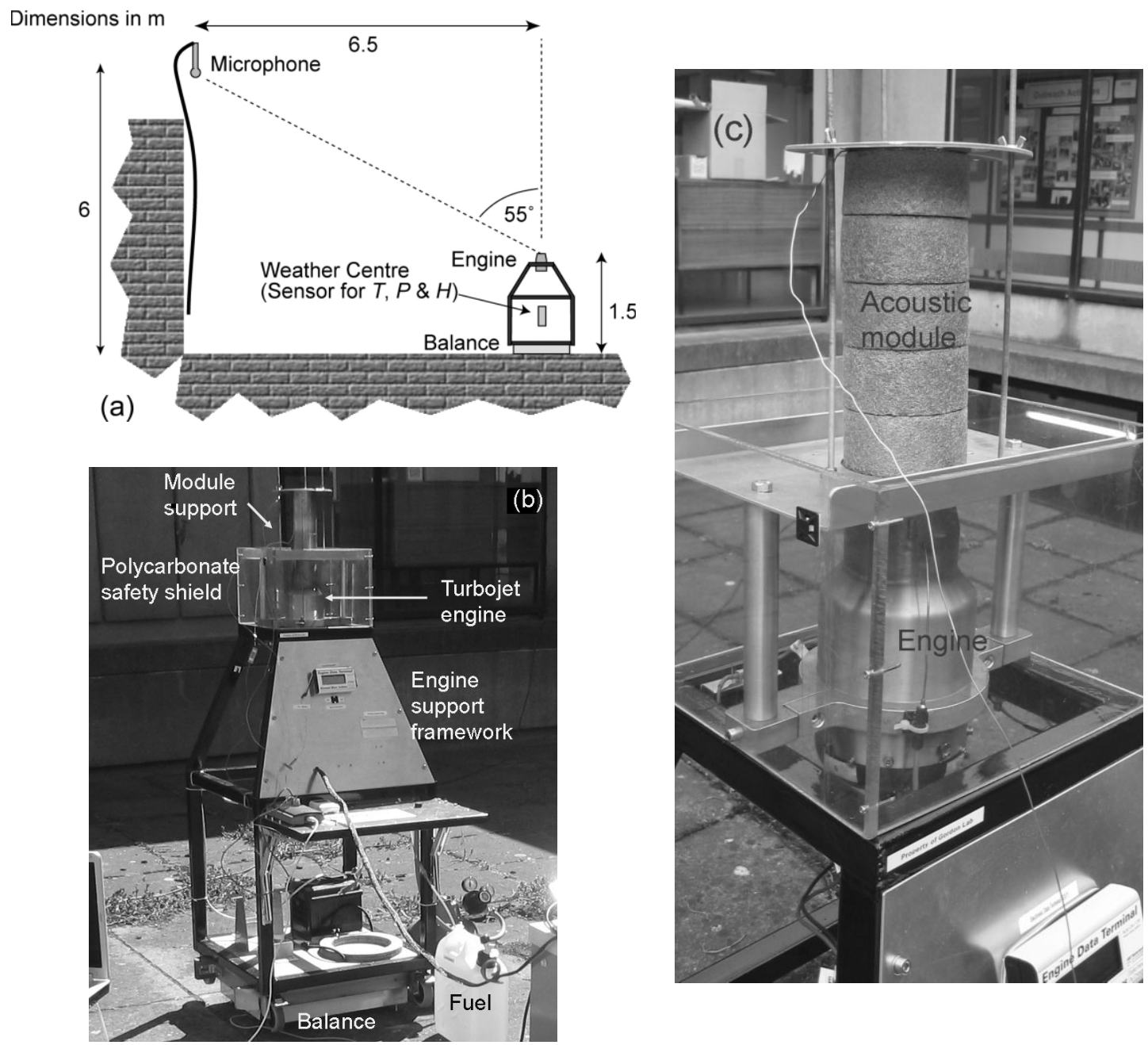

Fig. 2. Experimental arrangements: a). schematic of locations of engine and microphone, b). photo of set-up and c). close-up photo of engine, with an acoustic damping module in place (in this instance, a stack of 5 short cylinders, supported directly on the exhaust nozzle (no gap), with no tubular enclosure).

$115 \mathrm{~dB}$ SPL. The microphone was located in an identical position for each run (about $7.9 \mathrm{~m}$ from the exhaust nozzle, in a direction at $55^{\circ}$ to the engine axis - see Figure 2(a)). The runs were carried out on several different days, but in general the atmospheric conditions were similar on each occasion (wind speed below $5 \mathrm{~ms}^{-1}$, temperature $\sim 10-25^{\circ} \mathrm{C}$, pressure $\sim$ 1000-1030 mbar, relative humidity $\sim 40-60 \%$ ). In any event, comparisons between different cases (eg relative to the engine with no acoustic module) were only made for runs carried out on the same day. The day-to-day reproducibility of measured acoustic intensities for given cases was typically of the order of $1 \mathrm{~dB}$.

Typical engine performance data are shown in Figure 3, for a case in which the engine speed was ramped up and down over a period of about $8 \mathrm{~min}$. The thrust was measured with a high precision balance (Sartorius model Combics 1), on which the engine and support framework (which weighed about $60 \mathrm{~kg}$ ) was located during runs - see Figure 2(b). This balance measures up to about $100 \mathrm{~kg}$, with a resolution of $\pm 2 \mathrm{~g}$. Typical weight changes due to the thrust of the engine were of the order of $10 \mathrm{~kg}(\sim 100 \mathrm{~N})$, which could therefore
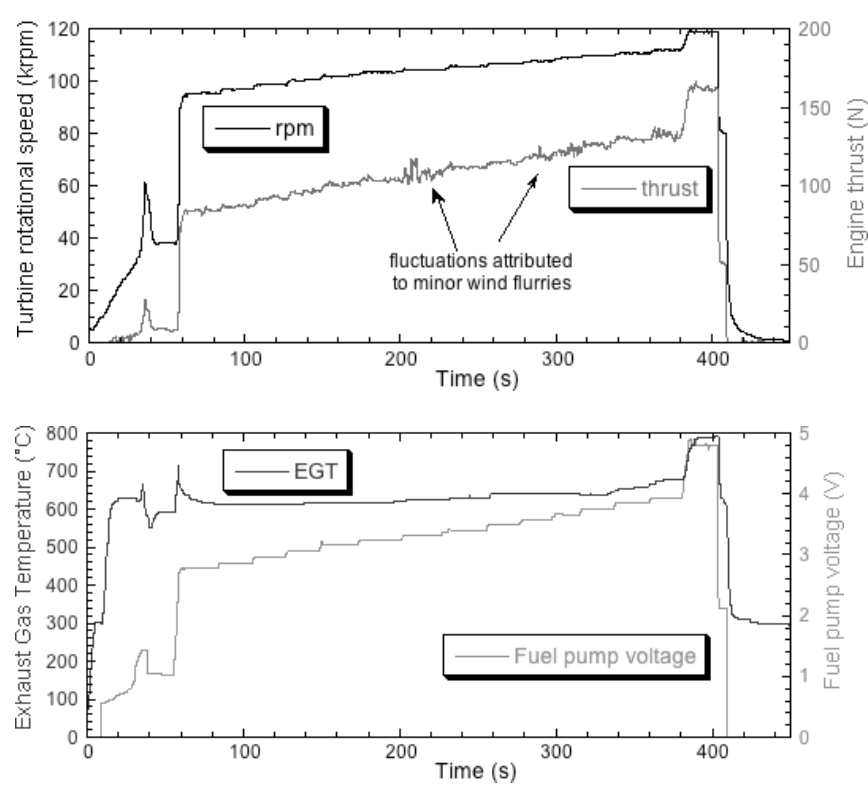

Fig. 3. Typical data for engine rpm, engine thrust, exhaust gas temperature and fuel consumption rate, during ramping up of engine speed. 
be measured to a precision of better than $0.1 \%$. However, some noise in the thrust data can be generated by small wind flurries etc, so thrust values in Table 1 are quoted to $\pm 1 \%$. For those runs, both acoustic plots and engine performance data are averaged values obtained over an integration period of about $10 \mathrm{~s}$.

The system dimensions in the vicinity of the exhaust nozzle are shown in Figure 4. The acoustic modules were supported either directly on the tapered outer surface of the nozzle (no gap), see Figure 4(c), or on a horizontal surface located so as to generate a small gap $(\sim 4.5 \mathrm{~mm})$ between it and the nozzle (Fig. 4(b)). In both cases, the module was held in place by firm downward pressure exerted via a top plate held in position with wing-nuts on lengths of studding - see Figures 2 and 4. For some runs, a large steel tube (bore $288 \mathrm{~mm}$, wall thickness $1.3 \mathrm{~mm}$ and length $250 \mathrm{~mm}$ ) was placed on the support assembly. In all cases, the engine and module/tube assembly exhibited radial symmetry. In no case
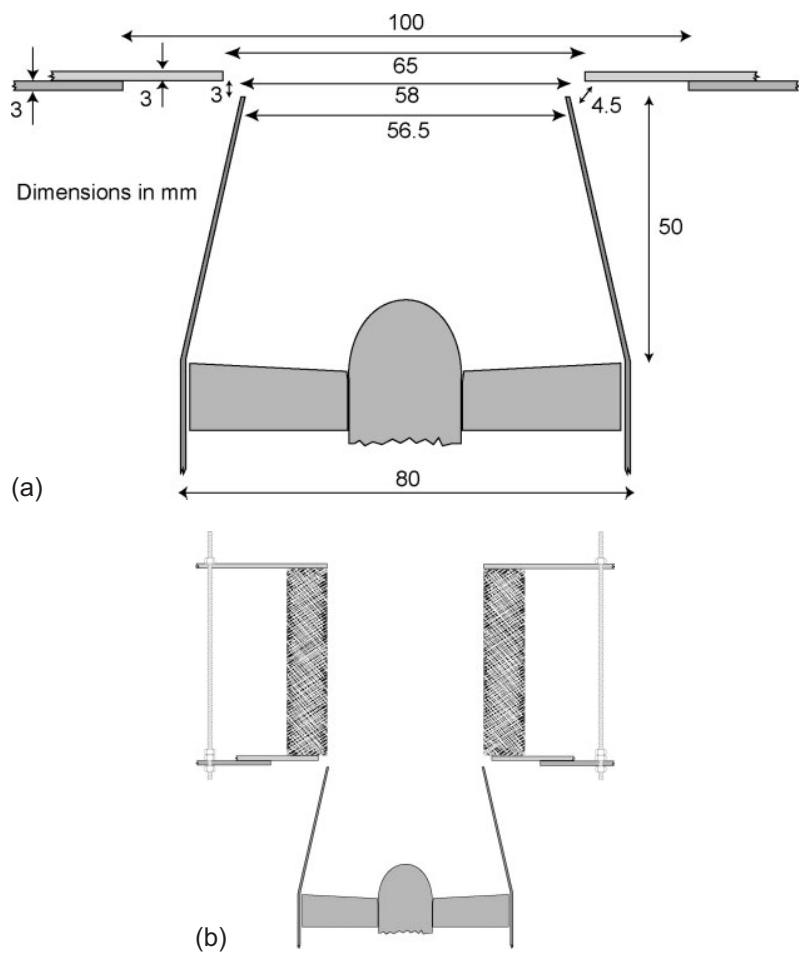

(c)

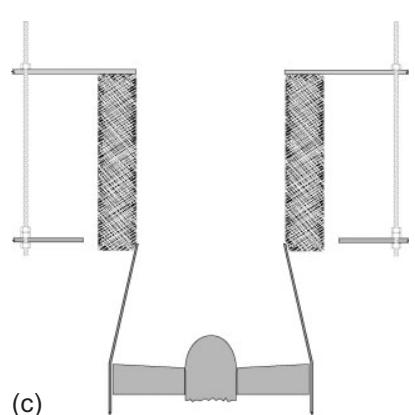

Fig. 4. Geometry of the exhaust region: a).Dimensions of exhaust nozzle and module support assembly, b).arrangement with a nozzle-module gap and c).arrangement with no nozzle-module gap. did the presence of modules or tubes appear to affect the operational stability of the engine in any way.

\section{Acoustic Characteristics and Engine Performance}

\section{General Features}

A comparison is shown in Figure 5(a) between acoustic spectra obtained with and without cylinders in the exhaust region, with the engine running close to maximum speed $(\sim 119 \mathrm{krpm})$. Several features are apparent. Firstly, the highest sound intensities are at frequencies in the approximate range $0.5-5 \mathrm{kHz}$. Both low ( few hundred $\mathrm{Hz}$ ) and high $(>\sim 15 \mathrm{kHz})$ frequencies can be ignored, particularly when account is taken of the Fletcher-Munson curves for the sensitivity of the human ear (see above). Secondly, while most of the noise represented in these spectra arises from the jet (exhaust region), there are some features associated with engine rotation - notably the main turbine peak, which is at

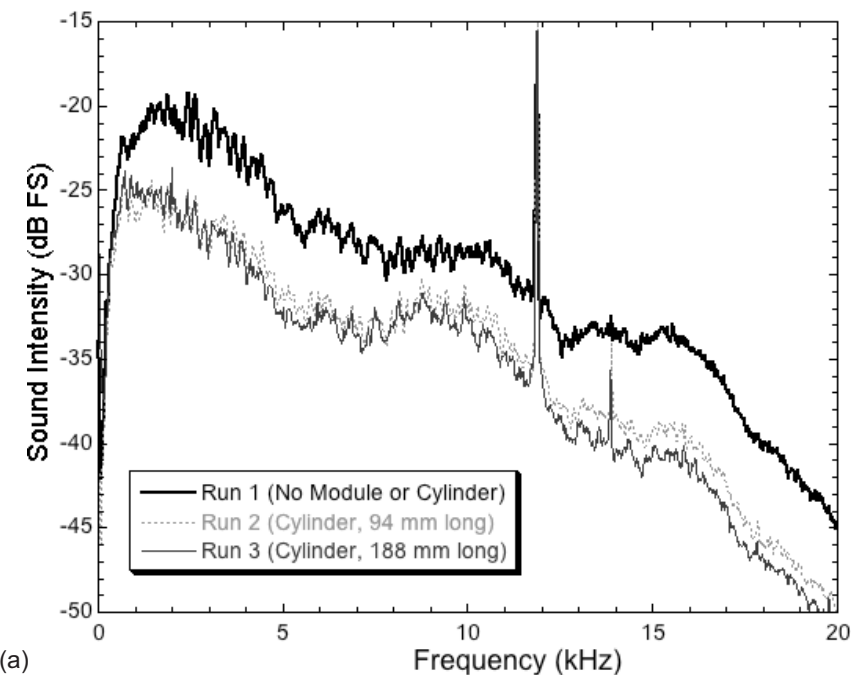

(b)

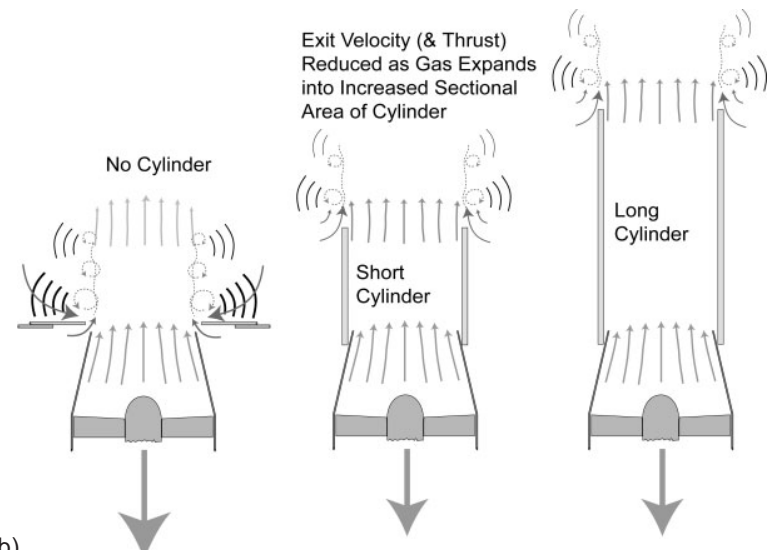

Fig. 5. a). Sound intensity as a function of frequency, for Runs 1, 2 and 3, showing the effect of the presence of a cylinder. $b$ ). Schematic depiction of how such cylinders can reduce the gas exit velocity, lowering both sound intensity and thrust. 
about $12 \mathrm{kHz}$ for this engine speed (and there is a harmonic at about $14 \mathrm{kHz}$ when the cylinders are present). Since turbine noise is not of direct interest in the present investigation, and in view of the above characteristics, further spectra in this paper cover only the $1-9 \mathrm{kHz}$ range.

It's also clear in Figure 5(a) that the noise level is reduced, over the complete spectral range, by the presence of the cylinders, with their length making little difference to the strength of the effect. However, it can be seen from the data in Table 1 that this has been achieved at the expense of sharply reduced thrust levels. While a small increase in fuel consumption might be considered an acceptable cost for a desirable noise reduction, it's clear that loss of thrust is not acceptable (since engine settings at different times during a flight are normally chosen so as to produce particular thrust levels). All further comparions presented in this paper therefore involve approximately equal thrust cases. In fact, fully dense material, such as the stainless steel of these cylinders, would not be expected to absorb noise significantly and the mechanism by which they influenced the noise spectrum in this instance is illustrated in Figure 5(b). As the exhaust gas expanded into an enclosure of increased sectional area, its velocity dropped, giving reductions in both thrust and noise intensity (which is very sensitive to velocity - see $\S 1$ ). Since the cylinders had smooth bores, there was little frictional drag and their length did not significantly affect the gas exit velocity. In any event, it's clear that any observed noise reduction needs to be properly understood, particularly in terms of whether acoustic absorption and/or lower levels of noise creation are primarily responsible.

\section{Acoustic Absorption within Modules}

\section{Effect of Module Length}

The effect of module length is illustrated by the data in Figure 6. Increased length was obtained by stacking individu-

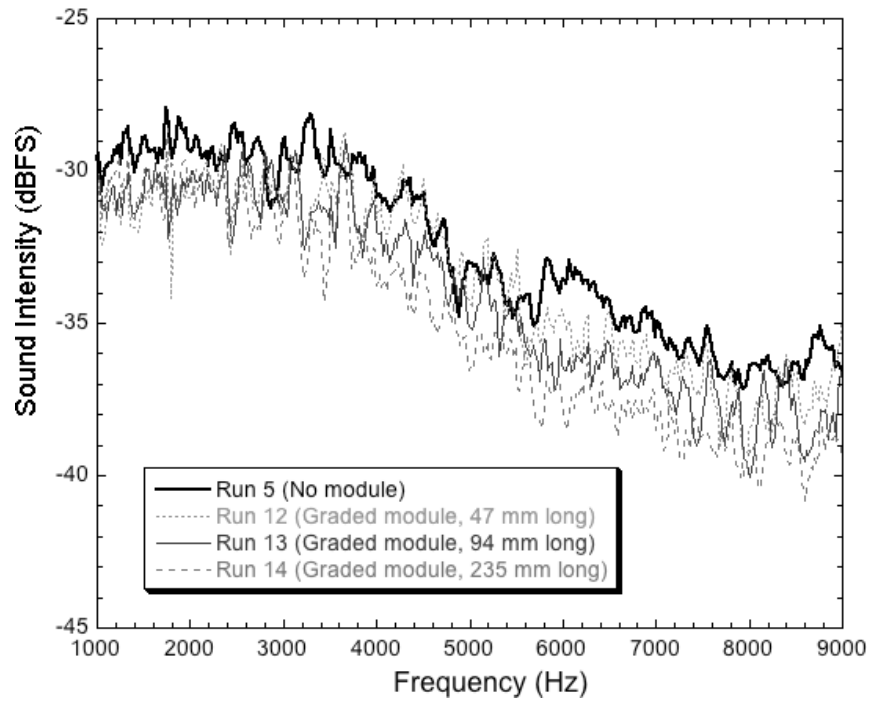

Fig. 6. Sound intensity as a function of frequency, for Runs 5, 12, 13 and 14, showing the effect of increasing the module length. al modules, all of which were about $47 \mathrm{~mm}$ long. Engine thrust was the same in all cases $(\sim 111 N$ - see Tab. 1$)$, although frictional drag on the rough inner surfaces of the modules meant that the engine speed had to be increased for the longer modules in order to achieve this, and this is reflected in the slightly higher fuel consumption rates for those cases. It can nevertheless be seen that there was a progressive decrease in the average noise level as the module length was increased. This is presumably due to increased acoustic attenuation. The effect is, however, clearly not linear with length and it would appear that there is little benefit from increasing the module aspect ratio (length/diameter) much above about two. For this specific case, a noise reduction of about $2-3 \mathrm{~dB}$ was obtained across most of the frequency spectrum.

Effects of Module Wall Thickness and Density Gradient: The effect of module wall thickness and architecture is illustrated by Figure 7 . Again these runs are all for cases of approximately equal engine thrust $(\sim 90 \mathrm{~N})$. It can be seen from the plots for the $10 \mathrm{~mm}$ thick modules, which have the same average density, that improved noise absorption is obtained by grading the density, with an improvement of about 1-2 $\mathrm{dB}$ in noise reduction being obtained across the spectrum. Comparison between the spectra for Runs 10 and 11 gives an indication of the effect of increasing the module thickness. For this case, it would appear that doubling the thickness, from 10 to $20 \mathrm{~mm}$, does not generate much further noise absorption, although this effect is probably rather specific to the dimensions of the set-up, and it may be that there would be benefits in having a greater module wall thickness than $10 \mathrm{~mm}$ in a larger engine.

\section{Effect of Enclosure}

In practice, any acoustic attenuation modules located in the exhaust region of an aeroengine are likely to be contained

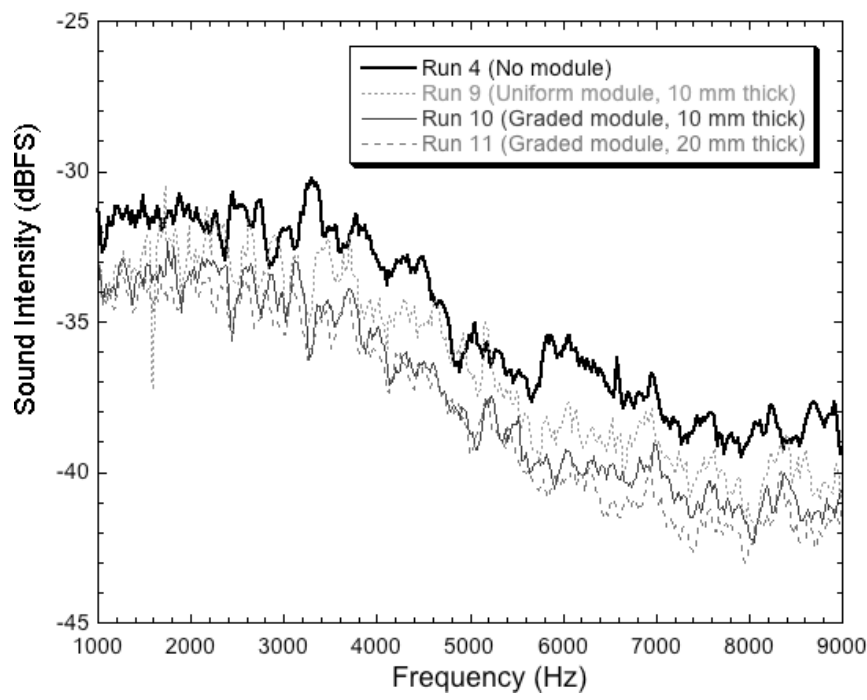

Fig. 7. Sound intensity as a function of frequency, for runs 4, 9, 10 and 11, showing the effects of introducing a radial density gradient and increasing the module wall thickness. 
within some kind of enclosure (with a fully dense wall). Such an enclosure will in any event affect the acoustic conditions, although in general it is not expected to absorb much noise and the main acoustic effect is likely to be reflection of sound waves back into the cavity (from where they are likely to emerge with the gas stream in due course). Acoustic spectra are shown in Figure 8(a) for cases in which the large steel tube was present $(290 \mathrm{~mm}$ bore, $1.3 \mathrm{~mm}$ wall thickness, $250 \mathrm{~mm}$ long), with and without an acoustic damping module contained within it. Several features are noticeable here. For example, there is increased noise (in both cases) at the low frequency end, and also a number of small peaks across the complete spectrum. These are probably resonance effects due to vibration of the tube. (Such vibrations would be much more heavily damped for the enclosure at the back of a real engine, which would normally be encased in some way.)

However, it's also clear that the acoustic module absorbed significant levels of noise (reductions of several $\mathrm{dB}$ ) under these conditions. This is particularly impressive when it is recognised that the module concerned had no density grading and was relatively thin (7 $\mathrm{mm}$ wall thickness). A possible explanation for the strength of the effect is illustrated in Fig-

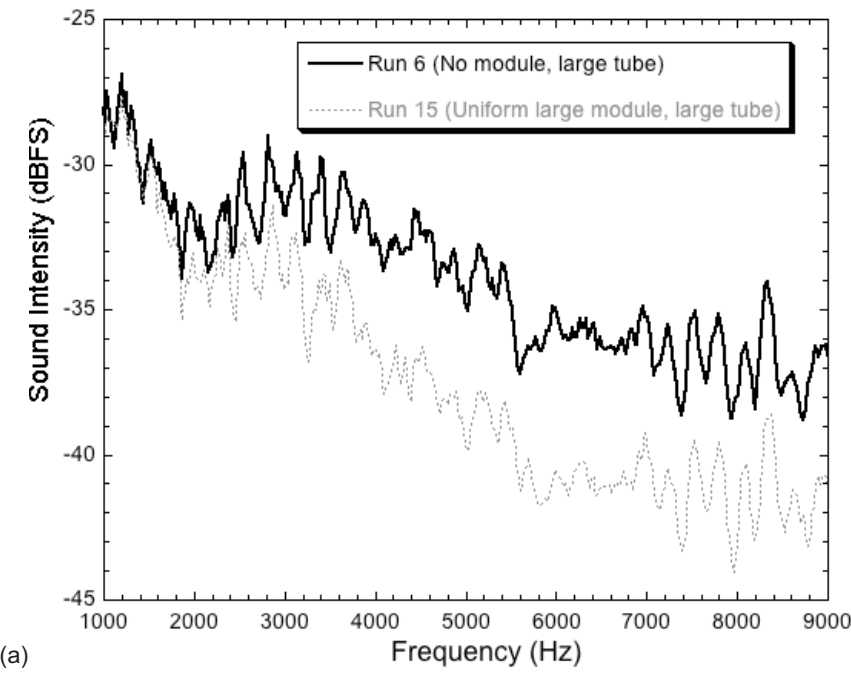

(a) Frequency $(\mathrm{Hz})$

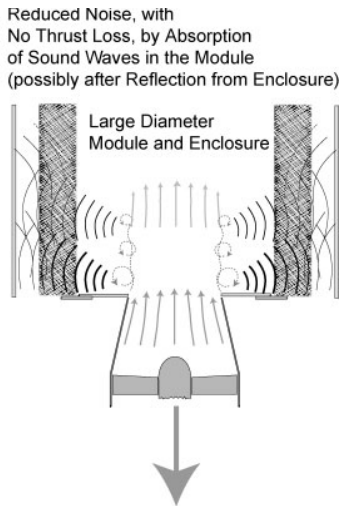

(b)

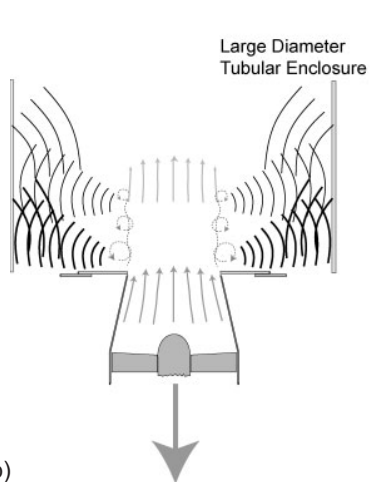

Loss, by Absorption of Sound Waves in the Module (possibly after Reflection from Enclosure)

Fig. 8. a). Sound intensity as a function of frequency, for Runs 6 and 15, showing the effect of the presence of a large tubular enclosure, with and without a large bore acoustic module. b). Schematic depiction of how an enclosure can lead to increased sound absorption in the module. ure $8(\mathrm{~b})$, where a schematic illustration is shown of how sound reflection from the enclosure may lead to repeated passage of sound waves through the acoustic module, increasing its absorption efficiency. Of course, this effect would be expected to operate in a real engine, especially if it had an extended exhaust enclosure region. It may be deduced that noise reductions of up to, say, $10 \mathrm{~dB}$ may be obtainable by acoustic attenuation mechanisms if a fibre network module of optimised design is deployed in this way.

\section{Effects of Modules on Gas Flow and Noise Creation}

It became clear from various experimental results that there is considerable scope for reducing noise levels by the introduction of components which alter the gas flow field so as to reduce the generation of noise. Figure 5 provides an example of this, although in that case there was no benefit from introducing the cylinders, because their effect was simply to reduce the gas exit velocity and hence the noise (and thrust). However, reductions in noise level at constant thrust can be obtained by influencing noise creation characteristics. An example is shown in Figure 9(a), which compares the effect
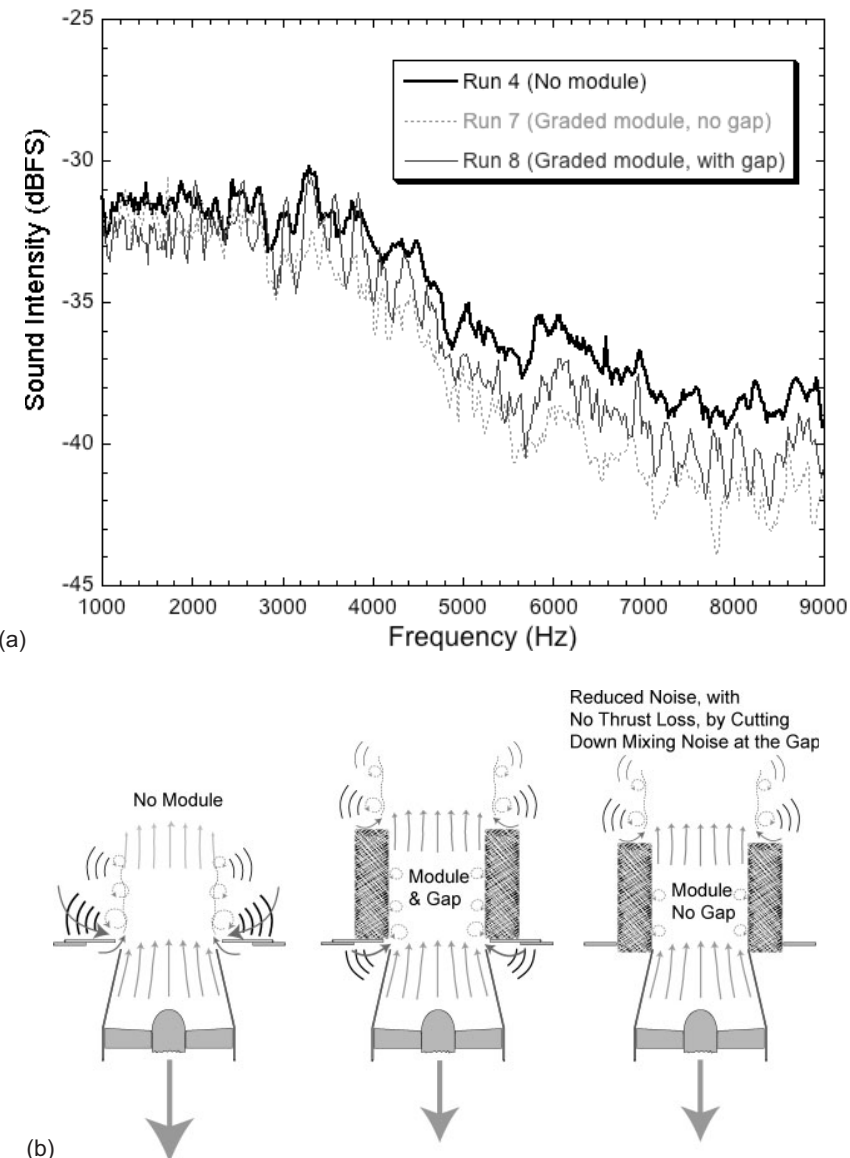

Fig. 9. a). Sound intensity as a function of frequency, for Runs 4, 7 and 8, showing the effect of the presence of a gap between nozzle exit and module. b) Schematic depiction of how the elimination of such a gap can modify the gas flow field so as to reduce sound creation. 
of the presence of a particular module with and without a gap between it and the exit nozzle. Since the associated displacement of the module was relatively small, the acoustic absorption within it was presumably similar for the two cases. However, the air entrainment conditions were altered, with less air flowing over the lip of the nozzle when the module was in contact with it, so that turbulence in the area was presumably reduced in that case - see Figure 9(b). It can be seen that there was an associated reduction in noise intensity of about 1-2 dB, with neither the thrust nor the fuel consumption rate being affected (see data in Tab. 1 for Runs 7 and 8).

Of course, effects of this type are likely to be specific to the geometry of the engine and the gas flow, so it is difficult to draw any universal conclusions from this result. However, it does suggest that significant noise reductions can be achieved in this way and in general it should be possible to design and locate acoustic modules so as to optimise, not only acoustic attenuation within them, but also their influence on the gas flow field. The fact that these modules have a relatively high permeability is relevant here, since this means that gas will tend to flow through them under the influence of a pressure gradient, but velocities and Reynolds numbers, and hence the tendency towards turbulence in the vicinity, may be sharply reduced. In relatively large engines, there may in particular be scope for reducing the levels of noise creation by ensuring that acoustic modules are located so as to render the mixing of core and by-pass gas flows less turbulent, although obviously this could not be specifically explored with the engine used in the present set of experiments.

\section{Conclusions}

The following conclusions can be drawn from this work.

A study has been made of the noise intensity, as a function of frequency, emitted by a small turbojet engine with and without various cylindrical acoustic modules located in the vicinity of the engine exhaust. The modules were made by sintering together short fibres of 304 stainless steel to produce highly porous material ( 10-15\% overall relative density), in some cases with increasing local density in the radial direction.

Noise reductions can be achieved by sound absorption within the modules and/or by their influencing the gas flow characteristics so as to reduce the generation of sound (typically by reducing the levels of turbulence associated with mixing of gas flows). While the latter effect is likely to be highly specific to the design of both engine and module, it has been shown that significant noise reduction can be achieved in this way with the small turbojet used in this study.

It has been shown that significant sound absorption can occur, across the complete frequency range of interest, within fibre network material of this type. In general, the results suggest that intensity reductions of, say, 5-10 dB should be routinely achievable via this mechanism by the introduction of lightweight acoustic modules. A "standard" module in the current work $(\sim 60 \mathrm{~mm}$ bore, $\sim 50 \mathrm{~mm}$ long, $\sim 10 \mathrm{~mm}$ wall thickness, $\sim 13 \%$ dense), which absorbed noise significantly, had a mass of $\sim 30 \mathrm{~g}$, ie $\sim 1 \%$ of the engine mass. For larger engines, the relative mass of an effective acoustic module is likely to be appreciably lower than this figure.

A study has been made of the influence of module architecture on the sound absorption characteristics. It has been shown that a small, but potentially significant, improvement in the noise reduction can be achieved by grading the density, such that it is lower on the inside, where the noise originates, and higher towards the outside. This is consistent with certain theoretical expectations.

The efficiency of noise absorption appears to be greater when a fully dense tubular enclosure is located around the acoustic module. It is suggested that this may be due to repeated passage of sound waves, reflected from the surface of the enclosure, through the module, with attenuation occurring during each transit. Such enclosures will commonly be present in any event with relatively large engines.

[1] N. H. Saiyed, K. L. Mikkelsen, J. E. Bridges, AIAA J. 2003, 41, 372.

[2] B. Callender, E. Gutmark, S. Martens, AIAA J. 2005, 43, 87.

[3] M. A. Galland, B. Mazeaud, N. Sellen, Appl. Acoustics 2005, 66, 691.

[4] M. Furstoss, D. Thenail, M. A. Galland, J. Sound Vibration 1997, 203, 219.

[5] K. Attenborough, Phys. Reports-Rev. Sec. of Phys. Lett. 1982, 82, 179.

[6] I. D. J. Dupere, A. P. Dowling, T. J. Lu, Cell. Ceram. Struct. Manufact. Properties and Appl. Ch. 4.5: Acoustic Properties, Wiley-VCH, Weinhelm, 2004.

[7] Z. Xie, T. Ikeda, Y. Okuda, H. Nakajima, Mat. Sci. Eng. A 2004, 386, 390.

[8] D. W. Robinson, R. S. Dadson, Br. J. Appl. Phys. 1956, 7 , 166.

[9] F. C. Sgard, X. Olny, N. Atalla, F. Castel, Appl. Acoustics 2005, 66, 625 .

[10] C. Boutin, P. Royer, J. L. Auriault, Int. J. Solids Struct. 1998, 35, 4709 .

[11] I. P. Dunn, W. A. Davern, Appl. Acoustics 1986, 19, 321.

[12] S. N. Y. Gerges, A. M. Balvedi, Appl. Acoustics 1999, 58, 403.

[13] D. H. Lee, Y. P. Kwon, J. Sound Vibration 2004, 278, 847.

[14] N. Atalla, R. Panneton, F. C. Sgard, X. Olny, J. Sound Vibration 2001, 243, 659.

[15] X. Olny, C. Boutin, J. Acoustical Soc. Am. 2003, 114, 73

[16] D. R. A. Christie, J. Sound Vibration, 1976, 46, 347.

[17] L. J. Gibson, Ann. Rev. Mater. Sci. 2000, 30, 191. 
[18] J. Banhart, Progr. Mater. Sci. 2001, 46, 559.

[19] J. Zhou, C. Mercer, W. O. Soboyejo, Metall. Mater. Trans. A 2002, 33, 1413.

[20] C. Motz, R. Pippan, Acta Mater. 2002, 50, 2013.

[21] T. W. Clyne, A. E. Markaki, J. C. Tan, Comp. Sci. Tech., 2005, 65, 2492.

[22] J. C. Tan, J. A. Elliott, T. W. Clyne, Adv. Eng. Mater. 2006, 8, 495 .

[23] A. E. Markaki, P. Colombo, T. W. Clyne, Highly Porous Cell. Met. and Ceram: Thermo-Mech. Properties, in Encyclopedia of Condensed Matter Physics, Elsevier, Oxford, 2005, 318.

[24] T. W. Clyne, I. O. Golosnoy, J. C. Tan, A. E. Markaki, Philos. Trans. Royal Soc. A - Math. Phys. Eng. Sci. 2006, $364,125$. 